\title{
Entomopathogenic fungi and their potential for the management of Aedes aegypti (Diptera: Culicidae) in the Americas
}

\author{
Harry C Evans ${ }^{1,2,3}$, Simon L Elliot ${ }^{2}$, Robert W Barreto ${ }^{3 /+}$ \\ ${ }^{1}$ Centre for Agriculture and Biosciences International, Egham, Surrey, UK \\ ${ }^{2}$ Universidade Federal de Viçosa, Departamento de Entomologia, Viçosa, MG, Brasil \\ ${ }^{3}$ Universidade Federal de Viçosa, Departamento de Fitopatologia, Viçosa, MG, Brasil
}

\begin{abstract}
Classical biological control has been used extensively for the management of exotic weeds and agricultural pests, but never for alien insect vectors of medical importance. This simple but elegant control strategy involves the introduction of coevolved natural enemies from the centre of origin of the target alien species. Aedes aegypti - the primary vector of the dengue, yellow fever and Zika flaviviruses - is just such an invasive alien in the Americas where it arrived accidentally from its West African home during the slave trade. Here, we introduce the concept of exploiting entomopathogenic fungi from Africa for the classical biological control of Ae. aegypti in the Americas. Fungal pathogens attacking arthropods are ubiquitous in tropical forests and are important components in the natural balance of arthropod populations. They can produce a range of specialised spore forms, as well as inducing a variety of bizarre behaviours in their hosts, in order to maximise infection. The fungal groups recorded as specialised pathogens of mosquito hosts worldwide are described and discussed. We opine that similar fungal pathogens will be found attacking and manipulating Ae. aegypti in African forests and that these could be employed for an economic, environmentally-safe and long-term solution to the flavivirus pandemics in the Americas.
\end{abstract}

Key words: Aedes mosquitoes - classical biological control - enemy release hypothesis - flaviviruses - infection strategies - pathogenic fungi

The flaviviruses have been posing threats to human health in the New World for the past four centuries, most notable has been the Yellow fever virus (YFV) (Flavivirus: Flaviviridae). It has even been conjectured that this virus influenced the balance of power and maritime geopolitics in the Americas after its arrival in the Caribbean region in the 1640s (Van der Weijden et al. 2007). Nevertheless, it could be argued that, in more recent times, Dengue virus (DENV) has far surpassed the impact of the YFV in the Americas, and is now "considered to be the most important mosquito-borne viral disease in the world" (Araújo et al. 2015a). Until recently, there were no vaccines or specific therapeutic agents to combat it (Simmons et al. 2012): a situation now changed with the report of a potential vaccine (Osorio et al. 2011), and the subsequent launch of Dengvaxia ${ }^{\circledR}$ (Sanofi-Pasteur). The global impact is immense with an estimated 50 million cases of dengue fever per year (WHO 2009); although this has been re-estimated at closer to 400 million (Bhatt et al. 2013). However, both these major human diseases have temporarily been surpassed in importance as Zika virus (ZIKV) has swept through the Americas; causing explosive pandemics (Fauci \& Morens 2016), and prompting the World Health Organization to declare a Public Health Emergency of International Concern

doi: 10.1590/0074-02760170369

Financial support: CAPES (grant no. 88881.068090/2014-01).

+ Corresponding author: rbarreto@ufv.br

Received 11 September 2017

Accepted 30 October 2017
(Gulland 2016, Musso \& Gubler 2016, Petersen et al. 2016, Russell 2016, Samarasekera \& Triunfol 2016). World attention has focused on this latest invasive flavivirus because of its purported association with congenital neurological disorders, such as microcephaly and Guillain-Barré syndrome (Gatherer \& Kohl 2016, Plourde \& Bloch 2016, Wikan \& Smith 2016). There is increasing and compelling evidence to confirm the supposition that the ZIKV is, indeed, the cause of these congenital defects (dos Santos \& Goldenberg 2016, Mlakar et al. 2016). The principal vector of all these exotic viruses in the Americas is Aedes aegypti (Diptera: Culicidae): often called the yellow fever mosquito and which, together with the flaviviruses, is also an invasive alien species from Africa (Powell \& Tabachnick 2013).

There are increasing calls for new strategies and products to improve the management of Ae. aegypti (Maciel-de-Freitas et al. 2012, Araújo et al. 2015a, Musso \& Gubler 2016, Petersen et al. 2016): highlighted by the article, "Zika virus outbreak in the Americas: the need for novel mosquito control methods" (Yakob \& Walker 2016). Similar calls for a broader and more integrated research approach that expands our knowledge of the complex ecosystems involved have been made (Fauci \& Morens 2016), especially in the light of claims that the various control campaigns launched by the Brazilian Government appear to have had little impact and that the battle against the mosquito is being lost (Araújo et al. 2015a, Samarasekera \& Triunfol 2016, Vogel 2016). Benelli et al. (2016) explored the use of biological control against mosquito vectors, including $A e$. aegypti, highlighting the potential of bacteria, especially Wolbachia. It was concluded that: "The paucity of studies describing 
the effects of fungi on mosquito populations indicates further research is needed" (Benelli et al. 2016).

Here, we assess and discuss the role that entomopathogenic fungi could play in managing Ae. aegypti in Latin America and opine that classical biological control - and, understanding the controlling factors and the natural balance of mosquito populations in Africa that comes with this approach - is just such an innovative vector control strategy.

The target: Ae. aegypti - The long-held assumption that the YFV and its mosquito vector first arrived in the Americas from Africa via the slave trade - purportedly, 'hitching a ride' in the bilges of sailing ships - has now been confirmed using gene sequence data to calculate divergence times (Bryant et al. 2007). Based on phylogenetic analyses, the latter authors calculated that the genetic variability in the South American virus arose within the last three to four centuries, offering support that the virus, along with Ae. aegypti, was introduced during the slave-trade era, when contact between Africa and the Americas was first made. The yellow fever mosquito is also an efficient vector of Chikungunya virus (CHIKV) (Alphavirus: Togaviridae) (Diallo et al. 2012), as well as the other flaviviruses: dengue (Moore et al. 2013, Powell \& Tabachnick 2013, Araújo et al. 2015a) and Zika (Diagne et al. 2015, Hennessey et al. 2016, Musso \& Gubler 2016, Solomon et al. 2016). Recent studies of mitochondrial DNA from exotic populations of Ae. aegypti have revealed a dual African origin: a basal clade from West Africa; and, a second clade - derived from this basal clade - present in East Africa (Bracco et al. 2007, Moore et al. 2013). Two genetically-distinct subspecies have now been confirmed: Ae. aegypti aegypti and Ae. aegypti formosus (Gloria-Soria et al. 2016). These co-occur in both East Africa (Kenya) and West Africa (Senegal). In forest habitats in Kenya, where formosus is the dominant and ancestral form (Yalwala et al. 2015), the two subspecies remain distinct but ingress freely in urban situations.

The increase in infestations of Ae. aegypti in subtropical and tropical regions of the Americas is considered to be an important factor in the Zika pandemic, and also in the on-going dengue outbreaks (Russell 2016). Rise in mosquito populations has been linked to increased urbanisation, improved transportation and resistance to insecticides (Dusfour et al. 2011, Maciel-de-Freitas et al. 2012, Flores et al. 2013, Hotez 2016). We also consider here that the absence of coevolved natural enemies has contributed significantly to the on-going situation, which is posited to be a key factor in invasions by alien species (Keane \& Crawley 2002). In fact, this is a re-invasion of South America by Ae. aegypti from foci in the Caribbean and North America, since the mosquito was mostly eradicated from the continent by the late 1960s, following almost two decades of an extensive and expensive campaign that involved both cultural (removal of breeding sites) and chemical control (Camargo 1967, Hotez 2016).

The strategy: classical biological control (CBC) - A major reason factored in to explain the success of invasive alien species (IAS) is the release from their natural enemies: encapsulated in the enemy release hypothesis
(Keane \& Crawley 2002). All species in their native ranges are host to natural enemies, either generalists or specialists: the latter have long associations with their hosts, which often generate a co-evolutionary relationship. Thus, escape from these natural enemies increases host fitness and can lead to population explosions, pest outbreaks and invasiveness. One well-established strategy for managing IAS - classical or inoculative biological control - has been to introduce host-specific or coevolved natural enemies in order to suppress the biotic invader and to restore the ecological balance that is lost when species escape their specialised natural enemies left behind in the evolutionary centre (Bellows 2001, Mitchell $\&$ Power 2003). CBC - or, "the intelligent introduction of counter-pests" (Elton 1958) - has been used extensively and, in many cases, very successfully as a management strategy for invasions by alien arthropods and plants; often, following the release of a single ('silver bullet') natural enemy. By far the greater majority of examples have involved insect agents: notably, parasitoids for invasive alien pests of crops (Neuenschwander 1996, Henry et al. 2010) and, insect herbivores for exotic weeds (McFadyen 1998); although, more recently, fungal plant pathogens have come to the fore (Evans 2013a). Moreover, it would not be an exaggeration to say that millions of lives and livelihoods have been saved, when subsistence and cash crops have been threatened by biotic invaders - especially in sub-Saharan Africa following the successes of the cassava mealybug, cassava green mite and the mango mealybug CBC programmes (Herren \& Neuenschwander 1991, Bokonon-Ganta et al. 2002, Moore 2004, Yaninek 2007) - whilst natural ecosystems have been conserved or restored (Hoddle 2004, Culliney 2005).

In contrast to the use of insect biocontrol agents, the exploitation of pathogenic fungi in $\mathrm{CBC}$ has been restricted, mainly because the practitioners have had an overwhelmingly entomological background, but also, in part, due to regulatory issues (Maddox et al. 1992) and pathophobia (Warner 2012), especially involving fungal pathogens of plants (Evans 2013a). Nevertheless, although the use of fungal agents for the $\mathrm{CBC}$ of invasive alien weeds has a relatively short history - compared to insect agents - there have been some notable successes in both agricultural and natural ecosystems (Evans 2013a); whilst for invasive insect pests, there are few examples where the classical strategy involving pathogenic fungi has been employed (Evans 2003, Hajek \& Delalibera 2010). Most of the history relating to the biological control of arthropod pests with fungi has involved the augmentative or inundative strategy with the development of formulated, semi-commercial or commercial products (mycoinsecticides), invariably based on generalist indigenous pathogens, most notably belonging to the genera Beauveria and Metarhizium (Jenkins et al. 1998, Inglis et al. 2001, Shah \& Pell 2003, Wraight et al. 2007). And, more recently, the well-trodden inundative approach has also received a significant amount of attention for the control of mosquito pests, particularly aimed at Anopheles vectors of malaria (Blanford et al. 2005, Scholte et al. 2005, Hughes \& Boomsma 2006, Scholte et al. 2008, Darbro et al. 2011, Blanford et al. 
2012). However, the question has been posed: "Should the much cheaper option of classical biological control, so successfully exploited for weed pathogens, be more closely pursued using entomopathogens for the management of alien arthropod pests?" (Evans 2003).

Entomopathogenic fungi as $C B C$ agents of invasive alien arthropods - The CBC strategy to control invasive alien arthropods with fungal pathogens - specifically, coevolved or old-encounter associations as opposed to generalist or new-encounter associations, such as Metarhizium anisopliae on mosquito hosts (Butt et al. 2013) - has rarely been used (Shah \& Pell 2003, Hajek 2007, Hajek et al. 2007, Hajek \& Delalibera 2010); and, never against mosquitoes (Weiser 1991, Scholte et al. 2004, RodriguézPérez et al. 2014). Of the few examples, however, success has been both unexpected and sustained, particularly since the $\mathrm{CBC}$ agents involved were obligate fungi of the order Entomophthorales which are fastidious and, seemingly, difficult to exploit. The first involves: "the miraculous appearance of an entomopathogenic fungus [Entomophaga maimaiga], which, soon after its appearance, started to decimate gypsy moth [Lymantria dispar] populations. It provides a good example of the 'enemy release hypothesis', because high populations of this pest are not common in its areas of origin [Asia] but severe outbreaks occur in North America where gypsy moth has invaded without its natural enemies" (Hajek 2007). The convoluted history of the classical introduction, and the confusion surrounding it, has been well documented (Andreadis \& Weseloh 1990, Hajek 1999, Pell et al. 2001, Hajek 2007). Suffice it to say that, with the aid of molecular tools, the virulent isolate of E. maimaiga which has kept pest populations in check originated in Japan, and far out-performed any of the other imported CBC agents: 13 insect natural enemies and one baculovirus (Hajek 2007). A similar success was achieved when an Israeli strain of Erynia (Zoophthora) radicans was released in Australia against the highly invasive spotted alfalfa aphid (Therioaphis trifolii). This aphid is no longer a major pest in Australia due, in part, to E. radicans but also aided by the introduction of a parasitic wasp (Pell et al. 2001, Shah \& Pell 2003).

Potential CBC agents of Ae. aegypti - The weapons of choice are entomopathogenic fungi because of their reported ubiquity and apparent diversity on mosquito hosts (Roberts 1970, Couch \& Bland 1985, Weiser 1991, Pell et al. 2001, Shah \& Pell 2003, Scholte et al. 2004, Wraight et al. 2007); and, on arthropods in general, most notably in tropical forest ecosystems (Samson et al. 1988).

"As the use of fungi to control mosquitoes has been proposed from time to time since before the turn of the century, this approach to population control can hardly be considered a novel one today" (Roberts 1970). However, in this first review of the subject, the latter author did indicate that most of the research had been of a taxonomic, rather than a practical nature and, therefore, that this approach was still wide open for exploration. In the second review, over 30 years later, the need to continue investigating the potential of entomopathogenic fungi - which had waned, in part, due to the discovery of the mosquitopathogenic bacterium, Bacillus thuringiensis israelensis
- was stressed because of "continuous and increasing levels of insecticide resistance and increasing global risk of mosquito-borne diseases" (Scholte et al. 2004). Only a decade on, with the pandemic spread of the flaviviruses, this would seem to be a prescient statement which appears to have fallen by the wayside. Here, the genera of fungi that have been recorded from natural populations of mosquitoes, in general, and from the genus Aedes, in particular, are listed and annotated as to their $\mathrm{CBC}$ potential.

Coelomomyces (Blastocladiomycota: Blastocladiales) - These are obligatory parasitic fungi with complex alternating life cycles - involving microcrustacean heteroecious hosts - and restricted to aquatic Diptera, including genera of Culicidae (e.g. Aedes, Anopheles, Culex); typically, the infected ovaries of adult females are infertile (Couch \& Bland 1985). Pathogenicity studies indicate that these are not host specific, although they may have restricted host ranges, and are frequently associated with epizootics. Nevertheless, as with some rust species (Evans 2013a), fungal pathogens with alternating life cycles are not considered to be suitable as $\mathrm{CBC}$ agents.

Entomophthora (Entomophthoromycotina: Entomophthorales) - A number of species are known from adult mosquitoes, including Entomophthora culicis and $E$. destruens from Culex species in Europe - where most insect-host records, in general, originate - and, the genus is often considered to have a predominantly Palaearctic distribution (Eilenberg 2000, Pell et al. 2001). Nevertheless, species of Entomophthora were also found to be common on adults of Culicidae in the tropical high forest of Ghana (Evans 1974). In total, eleven species of the genus Entomophthora have been linked to adult mosquitoes in the genera Aedes, Anopheles and Culex (Eilenberg 2000, Pell et al. 2001, Scholte et al. 2004). Thus, this genus holds some promise as a source of CBC agents of Ae. aegypti.

Erynia (Entomophthoromycotina: Entomophthorales) - Unusually, one species (Erynia aquatica) attacks both the larval and pupal stages of mosquitoes rather than just the adults, and, in North America it is associated with epizootics in populations of both Aedes canadensis and Ae. cantator (Anderson \& Ringo 1969, Andreadis \& Magnarelli 1983); whilst E. conica and E. radicans have been shown to infect adult Ae. aegypti in laboratory tests, with up to $100 \%$ infection (Scholte et al. 2004). Because Erynia has been linked directly with natural disease outbreaks on Aedes hosts - rather than just from lab-based pathogenicity tests - and its ability to infect all life stages, this genus has considerable potential and there is every reason to believe that host-specific Erynia species occur on Ae. aegypti in Africa.

Culicinomyces (Ascomycota: Pezizales) - Culicinomyces clavisporus is a facultative parasite of the larvae of a range of mosquito hosts, including Aedes, Anopheles and Culex, with infection of Ae aegypti being demonstrated in vitro (Scholte et al. 2004). Natural infections of Ae. kochi by a tropical species, C. bisporalis, have been reported from rainforest in Australia, following the collection of larvae from breeding sites in the leaf axils of understorey plants (Sigler et al. 1987). In laboratory 
tests, larvae of Ae. aegypti proved to be highly susceptible when challenged with the fungus (Sigler et al. 1987). This genus shows exceptional potential because of its occurrence in tropical forests on Aedes mosquitoes, as well as its ability to grow in vitro, and there is a high probability that Culicinomyces is associated with Ae.aegypti in its natural range in Africa.

Tolypocladium (Ascomycota: Hypocreales) - This large genus contains several species that are facultative parasites of mosquito larvae, including T. cylindrosporum - originally isolated from Ochlerotatus larvae in both the USA and New Zealand - which has been shown to be highly pathogenic to larvae of Anopheles and Culex in small-scale trials (Evans 2003, Scholte et al. 2004), as well as to Aedes triseriatus (Nadeau \& Boisvert 1994). Although this genus has not yet been recorded on Aedes under natural conditions, there is a possibility that it occurs on Ae. aegypti in African forest ecosystems.

It should be noted, however, that none of these genera have been isolated from Ae. aegypti in the field and, overwhelmingly, the studies to date have focused on temperate or subtropical regions in North America, Europe and Australasia - rather than from tropical Africa - and on diverse mosquito hosts. Moreover, laboratory pathogenicity tests can be misleading, in terms of host range and specificity, with frequent false positives and many records have been from experimental studies or from ad hoc field collections, with few, if any, field surveys targeted at the pathogenic mycobiota of mosquitoes. Also, note that the 'favoured' genera - traditionally employed in mycoinsecticides - have not been included here because, as observed previously (Roberts 1970): "The higher Beauveria and Metarhizium are not normally associated with mosquitoes and thus require repeated applications for use in control". This goes against the coevolved, sustainable (self-replicating) philosophy of CBC. In fact, a recent study on the use of Metarhizium for biological control of mosquitoes has shown the absence of a hostpathogen response and that Metarhizium has not evolved a specific mechanism to interact with mosquitoes (Butt et al. 2013) - supporting the much earlier held opinion of Roberts (1970), as well as Weiser (1991) - and that mortality is stress induced. In fact, subsequent studies have shown that this applies only to the dry conidia - which, in keeping with the greater majority of entomopathogenic fungi, only infect via the cuticle - and that the slimy blastospores produced in liquid culture can infect via the cuticle and, if ingested, also via the gut; making blastospores a much more efficient inoculum form for control of mosquito larvae (Alkhaibari et al. 2016). Nevertheless, the argument still holds that although effective control may initially be achieved by inundative application of such blastospore-containing products, this would not be sustainable and, as with chemical insecticides, repeated applications would be necessary.

Recently, the use of non-specialised, exotic biocontrol agents to tackle the Zika and dengue outbreaks in Brazil has been criticised as potentially harmful to the native biodiversity (Azevedo-Santos et al. 2016). In this case, 'mosquito fish' - generalist feeders belonging to non-na- tive species of the genus Poecilia - were being distributed within Brazil. This is the complete antithesis of the $\mathrm{CBC}$ strategy, which is based on the environmental safety guaranteed by using coevolved, host-specific natural enemies.

Evidence of the potential of $C B C$ - "The only intervention for Zika virus is mosquito control, which, for $A e-$ des mosquitoes, is notoriously difficult to sustain" (Solomon et al. 2016). Here, we put forward the case for CBC, which is founded on the premise that the coevolved natural enemy should be self-replicating once released into an exotic ecosystem; although, in urban situations where control is urgently needed or the target areas are vast such as with the cassava mealybug programme in Africa (Herren \& Neuenschwander 1991) - a highly-organised, technically-advanced, mass-production, classical-inundative strategy could also be employed. South American parasitoids of the invasive mealybug host were even encased for aerial delivery, and a much less refined massproduction, aerial application strategy was also used to control an invasive Madagascan weed with a coevolved rust fungus over vast areas of tropical Australia (Evans 2013a). This may be the case with Aedes in the Americas - for example, in high-risk urban systems - for which a product (biopesticide) could be developed for safe use in such priority situations, and which, potentially, could be self-sustaining once applied. The technology exists to mass-produce and formulate fungi in the Ascomycota (Jenkins et al. 1998, Inglis et al. 2001, Evans 2003) - such as Culicinomyces and Tolypocladium - and this approach could even be considered for certain obligate pathogens in the Entomophthoromycotina, since resting bodies and mycelia of some genera (e.g. Erynia) can be manipulated in vitro for field application (Shah et al. 1999).

The concept proposed here - that of using coevolved fungal pathogens - is under-pinned by the ability of these fungi to adapt to their hosts and to maximise infection by exploiting not only a range of spore types, but also the timing of spore release to coincide with host ecology: characteristics conspicuously absent in generalists, such as Beauveria and Metarhizium. For example, Culicinomyces bisporalis - discovered on Aedes larvae in a tropical rainforest (Sigler et al. 1987) - produces not only spores encased in mucilage, which may be an adaptation to an aquatic habitat, but also several other spore forms with, as yet, unknown functions in the infection cycle. Similarly, Erynia aquatica on larvae of Aedes species in floodwaters and marshes in North America exhibits different spore types (Anderson \& Ringo 1969, Andreadis \& Magnarelli 1983), and it is now known that the secondary spores, forcibly discharged from primary spores on larvae and pupae floating on the water, can infect newlyemerging adult mosquitoes (Samson et al. 1988, Roy et al. 2006); and, moreover, that this 'artificial' buoyancy is fungal-mediated. Other Entomophthorales - notably, aquatic Erynia species from temperate regions, such as E. conica on black flies (Simuliidae) - show remarkable adaptations with up to four spore types being produced by a single species to facilitate dispersal and infection, both aerially and aquatically, and revealing a great plasticity in spore morphology, as well as in mode of ger- 
mination (Samson et al. 1988, Pell et al. 2001, Roy et al. 2006). Furthermore, there is evidence that entomophthoralean fungi kill their hosts at specific times in synchrony with the climatic conditions that favour development and transmission of the pathogen (Roy et al. 2006).

In a final twist, there is increasing evidence that arthropod hosts, infected and killed by species of Entomophthorales, exhibit increased sexual attractiveness to potential mates: in essence, necrophilia with venereal disease implications. Males of Musca domestica, for example, are significantly more attracted to infected females than to healthy ones, and it has been conjectured that the fungus produces semiochemicals to attract the males (Roy et al. 2006). In addition, not only do these males become infected themselves, but females after mating with such males before they die, lay fewer eggs. Recent work on spider mites attacked by the entomophthoralean fungus Neozygites floridana confirms that the same fatal attraction is in operation: the males preferring females killed by the pathogen; whilst also exploring cadavers surrounded by fungal spore 'minefields' (Trandem et al. 2015). Obviously, such bizarre behaviour promotes transmission of the fungus and maximises infection rates.

Doubtless, the species of Entomophthorales common on dipteran hosts and collected by us during scoping surveys in a vestige of Atlantic rainforest in Brazil - as shown in Fig. 1 - possess similar diversity in spore form and function, as well as behavioural traits, to ensure infection of their low-density hosts. Unfortunately, however, information on this fungal group is sparse for tropical ecosystems. However, it may be prescient to consider recent studies on fungi in the Hypocreales, parasitic on ants in Neotropical forests, which have shown not only this plasticity in spore form and function, but also a hidden

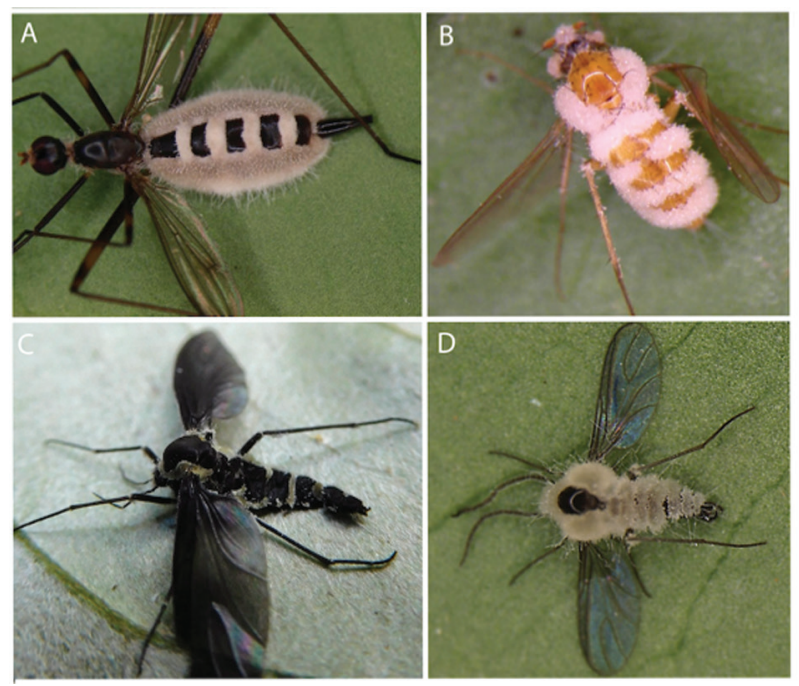

Fig. 1: examples of Entomophthorales infecting Dipteran hosts; all on underside of shrub leaves resulting from several days of collecting (April 2016), in fragment of Altantic rainforest, Minas Gerais, Brazil; (A-D) all hosts show bands of fungal mycelium emerging from the body sutures, sometimes enveloping the abdomen (A) or whole body (D), producing the forcibly-released spores (ballistospores); with (A, D), or without (B, C), obvious mycelial strands (rhizoids) attaching the host to the substrate.

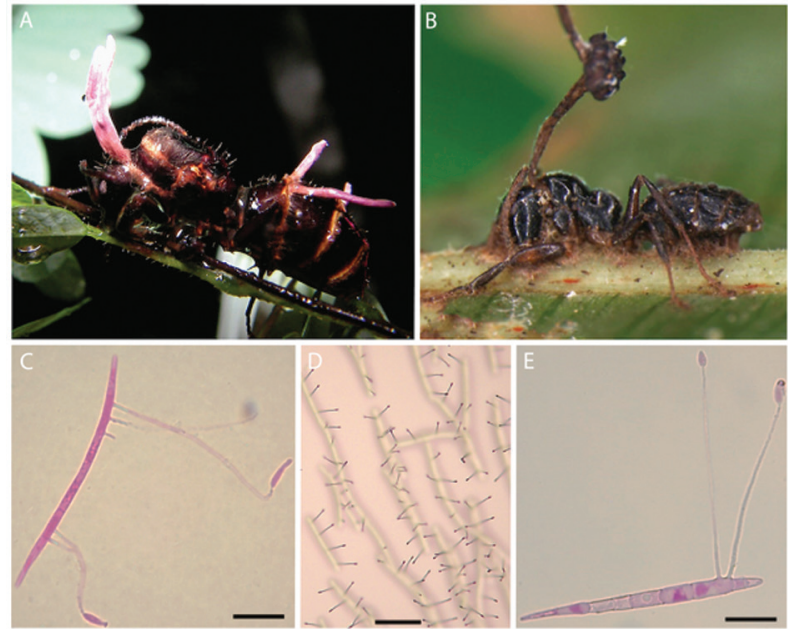

Fig. 2: spore form and function in the zombie-ant fungus, Ophiocordyceps unilateralis sensu lato; all collected at the same time and from the same locality as specimens in Fig. 1; (A) zombie-ant queen of Camponotus species, dying with its mandibles embedded in foliage of forest shrub and immature fungal structures emerging from sutures of upper neck and abdominal regions; (B) zombie-ant worker of a different species of Camponotus in a similar biting position, with mature sexual stage (ascostroma) emerging; (C-E) germinating ascospores, producing specialised needle-like outgrowths (capillisporophores) with sticky capillispores, analogous to the germination process in the Entomophthorales; note the ascospores deposited on a glass slide, producing rows of sticky 'traps' to attach to passing ants (D). Bars $=10 \mu \mathrm{m}$, except $\mathrm{E}=30 \mu \mathrm{m}$.

diversity revealing highly specific host-pathogen interactions (Evans et al. 2011, Araújo et al. 2015b, Hughes et al. 2016). The so-called zombie-ant fungus, Ophiocordyceps unilateralis sensu lato, found in Atlantic rainforest (Fig. $2 \mathrm{~A}-\mathrm{B})$ can have two-three asexual stages, to increase infection options, in addition to the characteristic sexual structure (ascostroma containing ascospores) emerging from the dorsal neck. The multiseptate, forcibly-released ascospores show a range of germination modes: producing secondary asexual stages (Fig. 2C); or, specialised needle-like capillisporophores with sticky spores (capillispores) at the apex (Fig. 2D-E). The capillispore stage is a remarkable example of convergent evolution, since the primary spores of some species of Entomophthorales also germinate to produce identical structures (Samson et al. 1988, Pell et al. 2001, Roy et al. 2006). Thus, 'minefields' are created on or below the vegetation on which the infected insects die, posing a threat to potential hosts randomly passing through or even specifically visiting them to oviposit or to feed (Evans et al. 2011, Araújo et al. 2015b, Hughes et al. 2016).

Finally, there is increasing evidence that arthropod hosts exhibit other behavioural changes when infected by fungal pathogens - the extended phenotype (Hughes 2013) - as, for example, in the order Hypocreales: the zombie ants climb shrubs and grip the foliage with mandibles and legs (Evans et al. 2011, Araújo et al. 2015b, Hughes et al. 2016) (Fig. 2A-B); ghost spiders leave their silken retreats and die on the undersides of leaves (Evans 2013b, Hughes et al. 2016). Similarly, hosts infected with 
Entomophthorales ascend vegetation (summit disease): subterranean sugar-beet aphids emerge above ground to die; carrot flies move away from the crop with the females altering their soil egg-laying habit so that they deposit their eggs on the foliage of hedgerow trees (Roy et al. 2006, Hughes et al. 2016, Gryganskyi et al. 2017). And certain genera - such as Strongswellsea on dipterans and Massospora on cicadas - even keep their infected hosts alive and the fungal spores are dispersed from body cavities during flight (Pell et al. 2001, Roy et al. 2006, Hughes et al. 2016). A recent comprehensive study of the Entomophthorales (COST 2007), has shown for the first time that the greater majority of species exhibit high levels of host specificity; mirroring that in the zombie-ant fungi of the Hypocreales (Evans et al. 2011, Araújo et al. 2015b, Hughes et al. 2016). In addition, latest research on the latter fungi has revealed that they produce a cascade of metabolites within the host - enzymes and enterotoxins - which can impact on functioning of the brain by changing the levels of neurotransmitters, such as serotonin and dopamine (de Bekker et al. 2015, Shang et al. 2015). These examples demonstrate that coevolved entomopathogenic fungi have developed a remarkable array of strategies to ensure that their spores reach the target hosts; and, furthermore, there is every reason to expect that fungi with similar traits will be found on endemic species of Aedes, such as Ae. aegypti, in Africa.

Realising the potential of $C B C$ - The first phase would be to conduct field surveys for fungal pathogens of Ae. aegypti in its African centres of origin or diversity. It has been established that the main breeding sites of sylvatic forms of Ae. aegypti - especially, the predominant sub-species formosus - is in forest tree holes, in both West Africa (Sylla et al. 2013) and East Africa (Yalwala et al. 2015). Sampling of these natural water containers for infected eggs and larvae should be the main collecting strategy, although this could be supplemented by the use of artificial containers (Yalwala et al. 2015). Other breeding sites - such as fruit husks - have also been identified (Sylla et al. 2013); offering another sampling niche. Fungal pathogens of the adult mosquitoes are more likely to be found on the understorey vegetation, but this would require an investigative period to determine the most appropriate niches to sample within the forest ecosystem.

It is envisaged that this survey phase would have a short time frame and that the potential of $\mathrm{CBC}$ - and thus the longer-term viability of the programme - could be determined within the first year. Once the samples have been processed, identified and catalogued, then the final decision can be made on the feasibility of $\mathrm{CBC}$ as a management strategy; obviously, this would be based on the presence or absence of novel, potentially-host specific or coevolved fungal pathogens. If the former prevails, then selected fungi would be assessed for host range, efficacy and pathogenicity, as well as undergoing risk assessments. As detailed previously, the traditional $\mathrm{CBC}$ approach is to release hosts infected with the fungus, usually an obligate pathogen, within the target pest populations - whether this be larvae or adults will depend on the spectrum of fungi meeting the selection cri- teria - and to await natural infection within these populations. Natural dissemination to disease-free populations would follow and thus the establishment of new inoculum sources for future epizootics. There is the distinct possibility that specific, non-obligate (able to grow in vitro) fungal pathogens will be also discovered in Africa. Thus, a two-pronged attack could be considered involving both the classic inoculative strategy as well as a separate inoculative-inundative approach - targeted at the larval stage - whereby a product could be mass-produced and applied as a mycoinsecticide for urban use. This would involve more time - and, potentially, industrial partners - as well as significantly more funding, to develop such a strategy. However, the expectation is that this inundative approach would be relatively short-term and that the fungus would be self-replicating within the urban situation, because of the adaptive traits previously detailed. Development of mass production and delivery techniques will depend firstly on the fungal species selected for use as a mycoinsecticide, but it is expected that the application strategy will be the same as that for conventional insecticides to access the breeding grounds of Ae. aegypti within the complex urban landscape. Certainly, the regulatory issues surrounding the exploration and use of components of the microbial biodiversity of the African countries, under the convention of biological diversity, will need to be addressed at an early stage in such projects and, ideally, this should involve scientists from these countries. Likewise, risk-analysis studies - involving both the safety of the agent to be used to non-target arthropods and to humans, including allergenic evaluations if a product were to be developed - will need to be dealt with in order for a formal permit of release to be issued by the relevant authorities in the importing country. The protocol involved is well established and has been tried and tested for exotic fungal pathogens against invasive alien weeds (Evans 2013a), and to a lesser extent against exotic arthropods (Hajek et al. 2007, Hajek \& Delalibera 2010).

In conclusion - We believe that classical biological control of Ae aegypti and, understanding the controlling factors and the natural balance of mosquito populations in Africa that comes with this approach - is just such an innovative vector control strategy that is currently being sought for the management of Zika virus, and related flaviviruses, in the Americas. Moreover, as the resources being allocated to control the pandemic are being assessed, according to their cost and the potential health benefits (Alfaro-Murillo et al. 2016), the cost effectiveness of $\mathrm{CBC}$ would far outweigh any of the other, more conventional management strategies presently on offer to decision-makers. In addition to being economically attractive, $\mathrm{CBC}$ should also be viewed as a long-term, proactive response rather than an essentially short-term reaction to the crisis, because - as demonstrated by the earlier eradication campaign (Hotez 2016) - the mosquito, as with any other invasive alien species, has the ability to re-invade or bounce back due to its increased fitness in the absence of coevolved natural-enemy pressure. Sustainable or on-going control of the primary 
vector Ae. aegypti must be the goal for the current pandemics in the Americas and, potentially, for those in the future when minor or as yet unknown viruses emerge from their forest homes in Africa and spread globally.

Based on the evidence presented, we posit that surveys in sylvatic habitats in both West and East Africa - concentrating on larval breeding sites of Ae. aegypti in epiphytes and tree crevices, as well as on foliage, for infected adults - will yield a range of coevolved natural enemies. Specifically, entomopathogenic fungi in the orders Entomophthorales, Hypocreales and Pezizales offer the most potential as $\mathrm{CBC}$ agents for the safe and sustainable management of Ae. aegypti in the Americas because of their demonstrated high host specificity; their proven ability to manipulate host behaviour and their plasticity of spore form and function in order to maximise infection. A multinational, multidisciplinary approach will be needed to test the hypothesis.

\section{ACKNOWLEDGEMENTS}

To the two anonymous reviewers for valuable inputs.

\section{AUTHORS' CONTRIBUTION}

RWB - Original idea; HCE - collection and processing of specimens, and literature review; HCE, SLE and RWB - manuscript preparation.

\section{REFERENCES}

Alfaro-Murillo JA, Parpia AS, Fitzpatrick MC, Tamagnan JA, Medlock J, Ndeffo-Mbah M, et al. A cost-effectiveness tool for informing policies on Zika virus control. PLoS Negl Trop Dis. 2016; 10(5): e0004743.

Alkhaibari AM, Carolino AT, Yavasogiu SI, Maffeis T, Mattoso TC, Bull JC, et al. Metarhizium brunneum blastospore pathogenesis in Aedes aegypti larvae: attack on several fronts accelerates mortality. PLoS Pathog. 2016; 12(7): e1005715.

Anderson JF, Ringo SL. Entomophthora aquatica sp. n. infecting larvae and pupae of floodwater mosquitoes. J Invert Pathol. 1969; 13(3): $386-93$.

Andreadis TG, Magnarelli LA. Erynia (=Entomophthora) aquatica in a salt-marsh mosquito, Aedes cantator. J Invert Pathol. 1983; 42(2): 277-9.

Andreadis TG, Weseloh RM. Discovery of Entomophaga maimaiga in North American gypsy moth, Lymantria dispar. Proc Natl Acad Sci USA. 1990; 87(7): 2461-5.

Araújo HRC, Carvalho DO, Ioshino RS, Costa-da-Silva AL, Capurro ML. Aedes aegypti control strategies in Brazil: incorporation of new technologies to overcome the persistence of dengue epidemics. Insects. 2015a; 6(4): 576-94.

Araújo JPM, Evans HC, Geiser DM, Mackay WP, Hughes DP. Unravelling the diversity behind the Ophiocordyceps unilateralis (Ophiocordycipitaceae) complex: three new species of zombie-ant fungi from the Brazilian Amazon. Phytotaxa. 2015b; 220(3): 224-38.

Azevedo-Santos VM, Vitule JRS, Pelicice FM, Simberloff D. Misguided strategy for mosquito control. Science. 2016; 351(6274): 674.

Bellows TS. Restoring population balance through natural enemy introductions. Biol Control. 2001; 21(3): 199-205.

Benelli G, Jeffries CL, Walker T. Biological control of mosquito vectors: past, present, and future. Insects. 2016; 7(4): 52.
Bhatt S, Gething PW, Brady OJ, Messina JP, Farlow AW, Moyes CL, et al. The global distribution and burden of dengue. Nature. 2013; 496(7446): 504-7.

Blanford S, Chan BHK, Jenkins N, Sim D, Turner RJ, Read AF, et al. Fungal pathogen reduces potential for malaria transmission. Science. 2005; 308(5728): 1638-41.

Blanford S, Jenkins NE, Read AF, Thomas MB. Evaluating the lethal and post-lethal effects of a range of fungi against adult Anopheles stephensi mosquitoes. Malar J. 2012; 11: 365.

Bokonon-Ganta AH, de Groote H, Neuenschwander P. Socio-economic impact of biological control of mango mealybug in Benin. Agric Ecosyst Environ. 2002; 93(3): 367-78.

Bracco JE, Capurro ML, Lourenço-de-Oliveira R, Sallum MAM. Genetic variability of Aedes aegypti in the Americas using a mitochondrial gene: evidence of multiple introductions. Mem Inst Oswaldo Cruz. 2007; 102(5): 573-80.

Bryant JE, Holmes EC, Barrett ADT. Out of Africa: a molecular perspective on the introduction of the yellow fever virus into the Americas. PLoS Pathog. 2007; 3(5): e75.

Butt TM, Greenfield BRJ, Greig C, Maffeis TGG, Taylor JWD, Piasecka J, et al. Metarhizium anisopliae pathogenesis of mosquito larvae: a verdict of accidental death. PLoS ONE. 2013; 8(12): e81686.

Camargo S. History of Aedes aegypti eradication in the Americas. Bull World Health Organization. 1967; 36(4): 602-3.

COST Action 842. Arthropod-pathogenic Entomophthorales. Luxembourg: EU Office; 2007.

Couch JN, Bland CE. The genus Coelomomyces. Orlando: Academic Press; 1985.

Culliney TW. Benefits of classical biological control for managing invasive plants. Crit Rev P1 Sci. 2005; 24(2): 131-50.

Darbro JM, Graham RI, Kay BH, Ryan PA, Thomas MB. Evaluation of entomopathogenic fungi as potential biological control agents of the dengue mosquito, Aedes aegypti (Diptera: Culicidae). Biocontrol Sci Technol. 2011; 21(9): 1027-47.

de Bekker C, Ohm RA, Loreto RG, Sebastian A, Albert I, Merrow $\mathrm{M}$, et al. Gene expression during zombie ant biting reflects the complexity underlying fungal parasitic behavioral manipulation. BMC Genomics. 2015; 16: 620.

Diagne CT, Diallo D, Faye O, Ba Y, Faye O, Gaye A, et al. Potential of selected Senegalese Aedes spp. mosquitoes (Diptera: Culicidae) to transmit Zika virus. BMC Infect Dis. 2015; 15: 492.

Diallo D, Sall AA, Buenemann M, Chen R, Faye O, Ba Y, et al. Landscape ecology of sylvatic Chikungunya virus and mosquito vectors in southeastern Senegal. PLoS Negl Trop Dis. 2012; 6(6): e1649.

dos Santos CND, Goldenberg S. Zika virus and microcephaly; challenges for a long-term agenda. Trends Parasitol. 2016; 32(7): 508-11.

Dusfour I, Thalmensy V, Gaborit P, Issaly J, Carinci R, Girod R. Multiple insecticide resistance in Aedes aegypti (Diptera: Culicidae) populations compromises the effectiveness of dengue vector control in French Guiana. Mem Inst Oswaldo Cruz. 2011; 106(3): 346-52.

Eilenberg J. Entomophthorales on Diptera. In: L Papp, B Darvas, editors. Manual of Palaearctic Diptera 13. Budapest: Science Herald; 2000. p. 521-33.

Elton CS. The ecology of invasions by animals and plants. London: Chapman and Hall; 1958.

Evans HC, Elliot SL, Hughes DP. Hidden diversity behind the zombie-ant fungus Ophiocordyceps unilateralis: four new species described from carpenter ants in Minas Gerais, Brazil. PLoS ONE. 2011; 6(3): e17024. 
Evans HC. Biological control of weeds with fungi. In: F Kempken, editor. The Mycota: agricultural applications XI, 2nd edition. Berlin: Springer; 2013a. p. 145-72.

Evans HC. Fungal pathogens of spiders. In: W Nentwig, editor. Spider ecophysiology. Berlin: Springer; 2013b. p. 107-21.

Evans HC. Natural control of arthropods, with special reference to ants (Formicidae), by fungi in the tropical high forest of Ghana. J Appl Ecol. 1974; 11(1): 37-49.

Evans HC. Use of clavicipitalean fungi for the biological control of arthropod pests. In: JF White, CW Bacon, NL Hywel-Jones, JW Spatafora, editors. Clavicipitalean fungi: evolutionary biology, chemistry, biocontrol and cultural impacts. New York: Dekker; 2003. p. 517-48.

Fauci AS, Morens DM. Zika virus in the Americas - yet another arbovirus threat. N Engl J Med. 2016; 374(7): 601-4.

Flores AE, Ponce G, Silva BG, Gutierrez SM, Bobadilla C, Lopez B, et al. Wide spread cross resistance to pyrethroids in Aedes aegypti (Diptera: Culicidae) from Veracruz state, Mexico. J Econ Entomol. 2013; 106(2): 959-69.

Gatherer D, Kohl, A. Zika virus: a previously slow pandemic spreads rapidly through the Americas. J Gen Virol. 2016; 97 (2): 269-73.

Gloria-Soria A, Ayala D, Bheecarry A, Calderon-Arguerdas O, Chadee DD, Chiaperro M, et al. Global genetic diversity of Aedes aegypti. Mol Ecol. 2016; 25(21): 5377-95.

Gryganskyi AP, Mullens BA, Gajdeczka MT, Rehner SA, Vilgalys R, Hajek AE. Hijacked: co-option of host behaviour by entomophthoralean fungi. PLoS Pathog. 2017; 13(5): e1006274.

Gulland A. Zika virus is a global health emergency: declares WHO. BMJ. 2016; 352: 1657.

Hajek AE, Delalibera I, McManus ML. Introduction of exotic pathogens and documentation of their establishment and impact. In: HK Kaya, LA Lacey, editors. Field manual of techniques in invertebrate pathology. 2nd ed. Dordrecht: Springer; 2007. p. 299-325.

Hajek AE, Delalibera I. Fungal pathogens as classical biological control agents against arthropods. Bio Control. 2010; 55(1): 1347-58.

Hajek AE, McManus ML, Delalibera I. A review of introductions of pathogens and nematodes for classical biological control of insects and mites. Biol Control. 2007; 41(1): 1-13.

Hajek AE. Introduction of a fungus into North America for control of gypsy moth. In: C Vincent, MS Goettel, G Lazarovits, editors. Biological control: a global perspective. Wallingford: CAB International; 2007. p. 53-62.

Hajek AE. Pathology and epizootiology of Entomophaga maimaga infections in forest Lepidoptera. Microbiol Mol Biol Rev. 1999; 63(4): 814-35.

Hennessey M, Fischer M, Staples JE. Zika virus spreads to new areas - Region of the Americas, May 2015-January 2016. MMWR. 2016; 65(3): 55-8.

Henry LM, May N, Acheampong S, Gillespie DR, Reitberg BD. Host-adapted parasitoids in biological control: does source matter? Ecol Appl. 2010; 20(1): 242-50.

Herren HR, Neuenschwander P. Biological control of cassava pests in Africa. Annu Rev Entomol. 1991; 36: 257-83.

Hoddle MS. Restoring balance: using exotic species to control invasive exotic species. Conserv Biol. 2004; 18(1): 38-49.

Hotez PJ. Zika in the United States of America and a fateful 1969 decision. PLoS Negl Trop Dis. 2016; 10(5): e0004765.

Hughes D. Pathways to understanding the extended phenotype of parasites in their hosts. J Exp Biol. 2013; 216(1): 142-7.
Hughes DP, Araújo JPM, Loreto RG, Quevillon L, de Bekker C, Evans HC. From so simple a beginning: the evolution of behavioral manipulation by fungi. Adv Gen. 2016; 94: 437-69.

Hughes DP, Boomsma JJ. Muscling out malaria. Trends Ecol Evol. 2006; 21(10): 533-4.

Inglis GD, Goettel MS, Butt TM, Strasser S. Use of hyphomycetous fungi for managing insect pests. In: TM Butt, C Jackson, N Magan, editors. Fungi as biocontrol agents: progress, problems and potential. Wallingford: CABI Publishing; 2001. p. 23-69.

Jenkins NE, Heviofo G, Langewald J, Cherry AJ, Lomer C. Development of mass production technology for aerial conidia for use as mycopesticides. Biocontrol News Inform. 1998; 19(1): 21-31N.

Keane RM, Crawley MJ. Exotic plant invasions and the enemy release hypothesis. Trends Ecol Evol. 2002; 17(4): 164-70.

Maciel-de-Freitas R, Aguiar R, Bruno RV, Guimarães MC, Lourenço-de-Oliveira R, Sorgine MHF, et al. Why do we need alternative tools to control mosquito-borne diseases in Latin America? Mem Inst Oswaldo Cruz. 2012; 107(6): 828-9.

Maddox JV, McManus ML, Jeffords MR, Webb RE. Exotic insect pathogens as classical biological control agents with an emphasis on regulatory considerations. In: WC Kauffman, JE Nechols, editors. Selection criteria and ecological consequences of importing natural enemies. Lanham, MD: Entomological Society of America; 1992. p. 27-39.

McFadyen REC. Biological control of weeds. Annu Rev Entomol. 1998; 43: 369-93.

Mitchell CE, Power AG. Release of invasive plants from fungal and viral pathogens. Nature. 2003; 421(6923): 625-7.

Mlakar J, Korva M, Tul N, Popović M, Poljšak-Prijatej M, Mraz J, et al. Zika virus associated with microcephaly. N Engl J Med. 2016; 374(10): 951-8.

Moore D. Biological control of Rastrococcus invadens. Biocontrol News Inform. 2004; 25(1): 17-27N.

Moore M, Sylla M, Goss L, Burugu MW, Sang R, Kamau LW, et al. Dual African origins of Aedes aegypti s.l. populations revealed by mitochondrial DNA. PLoS Negl Trop Dis. 2013; 7(4): e2175.

Musso D, Gubler DJ. Zika virus. Clin Microbiol Rev. 2016; 29(3): 487524.

Nadeau MP, Boisvert JL. Larvicidal activity of the entomopathogenic fungus Tolypocladium cylindrosporum (Deuteromycotina: Hyphomycetes) on the mosquito Aedes triseriatus and the black fly Simulium vittatum (Diptera: Simuliidae). J Am Mosq Control Assoc. $1994 ; 10(4)$ : 487-91.

Neuenschwander P. Evaluating the efficacy of biological control of three exotic homopteran pests. Entomophaga. 1996; 41(3): 405-24.

Osorio JE, Huang CY, Kinney RM, Stinchcomb DT. Development of DENVax: a chimeric dengue-2 PDK-53-based tetravalent vaccine for protection against dengue fever. Vaccine. 2011; 29(42): 7251-60.

Pell JK, Eilenberg J, Hajek AE, Steinkraus DC. Biology, ecology and pest management potential of Entomophthorales. In: TM Butt, C Jackson, $\mathrm{N}$ Magan, editors. Fungi as biocontrol agents: progress, problems and potential. Wallingford: CABI Publishing; 2001. p. 71-153.

Petersen LR, Jamieson DJ, Powers AM, Honein MA. Zika virus. N Engl J Med. 2016; 374(16): 1552-63.

Plourde AR, Bloch EM. A literature review of Zika virus. Emerg Infect Dis. 2016; 22(7): 1185-92.

Powell JR, Tabachnick WJ. History of domestication and spread of Aedes aegypti - A Review. Mem Inst Oswaldo Cruz. 2013; 108(Suppl. 1): 11-7. 
Roberts DW. Coelomomyces, Entomophthora, Beauveria, and Metarrhizium as parasites of mosquitoes. Misc Publ Entomol Soc Am. 1970; 7(1): 140-55.

Rodriguéz-Pérez MA, Howard AFV, Reyes-Villaneuva F. Biological control of dengue vectors. In: S Soluneski, editor. Integrated pest management and pest control - current and future tactics. Rikeka: InTech; 2014. p. 241-70.

Roy HE, Steinkraus DC, Eilenberg J, Hajek AE, Pell JK. Bizarre interactions and endgames: entomopathogenic fungi and their arthropod hosts. Annu Rev Entomol. 2006; 51: 331-57.

Russell PK. The Zika pandemic - a perfect storm? PLoS Negl Trop Dis. 2016; 10(3): e0004589.

Samarasekera U, Triunfol M. Concern over Zika grips the world. Lancet. $2016 ; 387(10018): 521-4$.

Samson RA, Evans HC, Latgé J-P. Atlas of entomopathogenic fungi. Berlin: Springer; 1988.

Scholte E-J, Knols BGJ, Samson RA, Takken W. Entomopathogenic fungi for mosquito control: a review. J Insect Sci. 2004; 4(1): 1-24.

Scholte E-J, Knols BGJ, Takken W. An entomopathogenic fungus (Metarhizium anisopliae) for control of the adult African malaria vector Anopheles gambiae. Entomologische Berichten. 2008; 68(1): $21-6$

Scholte E-J, Nghabi K, Kihonda J, Takken W, Paaijmans K, Abdulla $\mathrm{S}$, et al. An entomopathogenic fungus for control of adult African malaria mosquitoes. Science. 2005; 308(5728): 1641-2.

Shah PA, Aebi M, Tuor U. Production factors involved in the formulation of Erynia neoaphidis as alginate granules. Biocontrol Sci Technol. 1999; 9(1): 19-28.

Shah PA, Pell JK. Entomopathogenic fungi as biological control agents. Appl Microbiol Biotechnol. 2003; 61(5): 413-23.

Shang Y, Feng P, Wang C. Fungi that infect insects: altering host behaviour and beyond. PLoS Pathog. 2015; 11(8): e1005037.

Sigler L, Frances SP, Panter C. Culicinomyces bisporalis, a new entomopathogenic hyphomycete from larvae of the mosquito Aedes kochi. Mycologia. 1987; 79(4): 493-500.

Simmons CP, Farrar JJ, Chau NV, Wills B. Dengue. N Engl J Med. 2012; 366(15): 1423-32.
Solomon T, Baylis M, Brown D. Zika virus and neurological disease approaches to the unknown. Lancet. 2016; 16(4): 402-4.

Sylla M, Ndiaye M, Black WC. Aedes species in treeholes and fruit husks between dry and wet seasons in southeastern Senegal. J Vector Ecol. 2013; 38(2): 237-44.

Trandem N, Bhattarai UR, Westrum K, Knudsen GK, Klingen I. Fatal attraction: male spider mites prefer females killed by the mite-pathogenic fungus Neozygites floridana. J Invert Pathol. 2015; 128(1): 6-13.

Van der Weijden W, Leewis R, Bol P. Biological globalisation: bio-invasions and their impacts on nature, the economy and public health. Utrecht: KNNV Publishing; 2007.

Vogel G. Mosquito hunters search for Zika vectors. Science. 2016; 352(6290): 1152-3.

Warner KD. Fighting pathophobia: how to construct constructive public engagement with biocontrol without augmenting public fears. Bio Control. 2012; 57(2): 307-17.

Weiser J. Biological control of vectors. Chichester: Wiley; 1991.

WHO - World Health Organization. Dengue: guidelines for treatment, prevention and control. Geneva: World Health Organization; 2009.

Wikan N, Smith DR. Zika virus: history of a newly emerging arbovirus. Lancet Infect Dis. 2016; 16(7): e119-26.

Wraight SP, Inglis GD, Goettel MS. Fungi. In: HK Kaya, LA Lacey, editors. Field manual of techniques in invertebrate pathology. 2nd ed. Dordrecht: Springer; 2007. p. 223-48.

Yakob L, Walker T. Zika virus outbreak in the Americas: the need for novel mosquito control methods. Lancet Global Health. 2016; 4(3): e148-9.

Yalwala S, Clark J, Oullo D, Ngonga D, Abuom D, Wanja E, et al. Comparative efficacy of existing surveillance tools for Aedes aegypti in Western Kenya. J Vector Ecol. 2015; 40(2): 301-7.

Yaninek S. Biological control of the cassava green mite in Africa: overcoming challenges to implementation. In: $\mathrm{C}$ Vincent, MS Goettel, G Lazarovits, editors. Biological control: a global perspective. Wallingford: CAB International; 2007. p. 28-37. 